Cadernos de

Pesquisa do CDHIS DOI: https://doi.org/10.14393/cdhis.v32n2.2019.52165

\title{
A FESTA DO SENHOR DOS PASSOS EM SÃO CRISTÓVÃO/SE, A PARTIR DAS MEMÓRIAS DE DONA NENÉM
} THE PARTY OF LORD OF THE STEPS IN SÃO CRISTÓVÃO/SE,
FROM THE MEMORIES OF "DONA NENÉM"

Ivan Rêgo Aragão ${ }^{1}$

Hermeson Alves de Menezes $^{2}$

Em memória de D. Maria Luiza dos Santos.

\footnotetext{
${ }^{1}$ Professor do curso de Pedagogia (UNIT/EaD) e da pós graduação em Ensino de História do Brasil (UNIT). Mestre em Cultura e Turismo (UESC). Licenciado em História (UNIT). Bacharel em Turismo (Estácio/FaSe).

2 Professor Adjunto no curso de Licenciatura em História, coordenador e professor da pós graduação em Ensino de História do Brasil (UNIT). Mestre em Educação e Licenciado em História (UFS).
} 


\section{Resumo}

Memória, elemento chave que traz para atualidade acontecimentos passados vêm sendo utilizada como ferramenta de trabalho e suporte para a pesquisa do historiador. Pessoas em idades avançadas além do conhecimento de vida, traz em suas lembranças, fatos vivenciados que são registros cotidianos, traduzindo costumes sociais de diversas fases da vida. Sendo assim, a partir da pesquisa bibliográfica, trabalho de campo para escuta e posterior transcrição da fala da depoente o presente artigo visa expôr as memórias de Maria Luiza dos Santos, mais conhecida como D. Neném. Estas memórias estão vinculadas à Festa do Senhor dos Passos. O texto em questão analisa mudanças e recorrências na comemoração religiosa a partir das lembranças de uma fonte oral e verifica quais memórias relativas aos aspectos da Festa do Senhor dos Passos são priorizadas pela depoente anciã. Dona Neném ao expor suas lembranças, selecionadas a partir do roteiro de perguntas traz à luz fatos da comemoração do Senhor dos Passos na cidade de São Cristóvão passiveis de serem verificados como mudanças e permanências ao longo do século XX e primerios anos do XXI.

Palavras-chave: Memória; História Oral; Lembranças de Idosos.

\begin{abstract}
Memory, key element that brings to current events past has long been used as a work tool and support for the historian's research. People in advanced ages beyond the knowledge of life, brings in their memories, facts experienced that are daily records, translating social customs of different phases of life. Thus, from the bibliographic research, fieldwork for listening and subsequent transcription of the speech of the interviewees this article aims to expose the memories of Maria Luiza dos Santos, better known as D. Neném. Memories are linked to the Party of the Lord of Steps. The text in question analyzes changes and recurrences in the religious commemoration from the memories of an oral source and verifies which memories related to the aspects of the Party of the Lord of the Steps are prioritized by the elder responent. Dona Neném when exposing her memories, selected from the script of questions brings to light facts of the commemoration in the city of São Cristóvão susceptible to be verified as changes and permanences throughout the $X X$ century and first years of the XXI.
\end{abstract}

Keywords: Memory; Oral history; OldAge Memories.

\section{Introdução}

Pensar a festa de Nosso Senhor dos Passos na cidade sergipana de São Cristóvão é refletir sobre o conjunto de elementos que compõem o patrimônio cultural envovido na celebração religiosa. Dentre esses aspectos culturais, encontram-se as memórias de indivíduos mais idosos que presenciaram por quase 
um século o citado acontecimento festivo. Segundo informa Macena (2003, p. 63), pode ser enquadrado como patrimônio "[...] tudo o que existe como elemento essencial para o registro da memória individual e coletiva, e que possa contribuir com a formação do sentimento de pertença de uma comunidade". Entende-se por esse elemento cultural, pessoas e seus testemunhos oculares, patrimônio humano, vivo e dinâmico.

Nesse contexto, memórias seletivas, lembranças afetivas e esquecimentos inconscientes perfazem o conjunto da herança cultural advinda dos devotos, fiéis e penitentes mais idosos no transcorrer dos anos da Festa de Nosso Senhor dos Passos. Quando se verifica a vivência de uma parcela de indivíduos partícipes durante o período da citada celebração, constata-se um acúmulo natural de experiências que foram apropriadas pelos sentidos e que se estratificaram em lembranças.

Tendo como influências a dissertação de mestrado em cultura e turismo defendida no ano de 2012, na Universidade Estadual de Santa Cruz e aulas de teorias da história na licenciatura em História em 2018, pela Universidade Tiradentes, o artigo em questão, foi construído a partir das técnicas de investigação da pesquisa bibliográfica para o aporte conceitual, trabalho de campo para escuta e posterior transcrição da fala da depoente. O texto além de expôr as memórias de Maria Luiza dos Santos, mais conhecida como D. Neném - memórias estas vinculadas à Festa do Senhor dos Passos - também visa analisar mudanças e recorrências na comemoração religiosa a partir das lembranças de uma fonte oral, verificando quais memórias relativas aos aspectos da Festa do Senhor dos Passos foram priorizadas pela depoente.

Lembranças que emergem sobre a Festa do Senhor dos Passos, contextualizando-a no patrimônio cultural e humano. D. Neném estaria com 105 anos, no entanto à época do colhimento das informações encontrava-se com a idade de 98 anos. Devota do Senhor dos Passos, Dona Maria Luiza dos Santos foi membro da comissão da citada festa religiosa, além de brincante de grupos folclóricos na 
cidade. Ela cômpos um grupo de entrevistados de diferentes idades, sendo a que tinha a maior faixa etária. Bastante idosa e portadora de deficiência visual, D. Neném tinha em suas lembranças registros de fatos passados na cidade de São Cristóvão, principalmente sobre a Festa do Senhor dos Passos. Bosi (1979) menciona que os idosos fazem parte de uma classe socialmente oprimida principlamente pelo fator "velhice". São atores sociais que quase sempre são postos de lado numa sociedade que previlegia a atividade, a ação, o fazer, a produção. Dessa forma é intenção do artigo trazer à tona e destacar as memórias sobre a Festa do Senhor dos Passos por uma das moradoras mais anciãs da comunidade sãocristovense portadora de registros oculares passados sobre o cotidiano festivo do Senhor dos Passos.

\section{Festa Centenária do Senhor dos Passos em Sergipe}

No centro antigo da cidade sergipana de São Cristóvão, a $26 \mathrm{~km}$ da capital Aracaju é realizada a Festa com a Procissão ao Nosso Senhor dos Passos (Figura 1). O evento anual é comemorado no segundo final de semana após o Carnaval e, em média, quinze dias antes da Semana da Santa. O Inventário de Bens Móveis e Integrados do Instituto do Patrimônio Histórico e Artística Nacional (IPHAN), a partir de entrevistas com pessoas responsáveis pela comemoração, informa que a Festa de Passos inicou a ser documentada a partir do ano da transferência da capital, que foi em $1855^{3}$ (BRASIL, 2001).

\footnotetext{
${ }^{3}$ A mudança da capital sergipana ocorreu em 17 de março de 1855, quando o presidente da província de Sergipe na época, Inácio Barbosa, elevou a categoria de cidade o povoado de Santo Antônio do Aracaju e efetivou a mudança da capital de São Cristóvão para a nova cidade.
} 


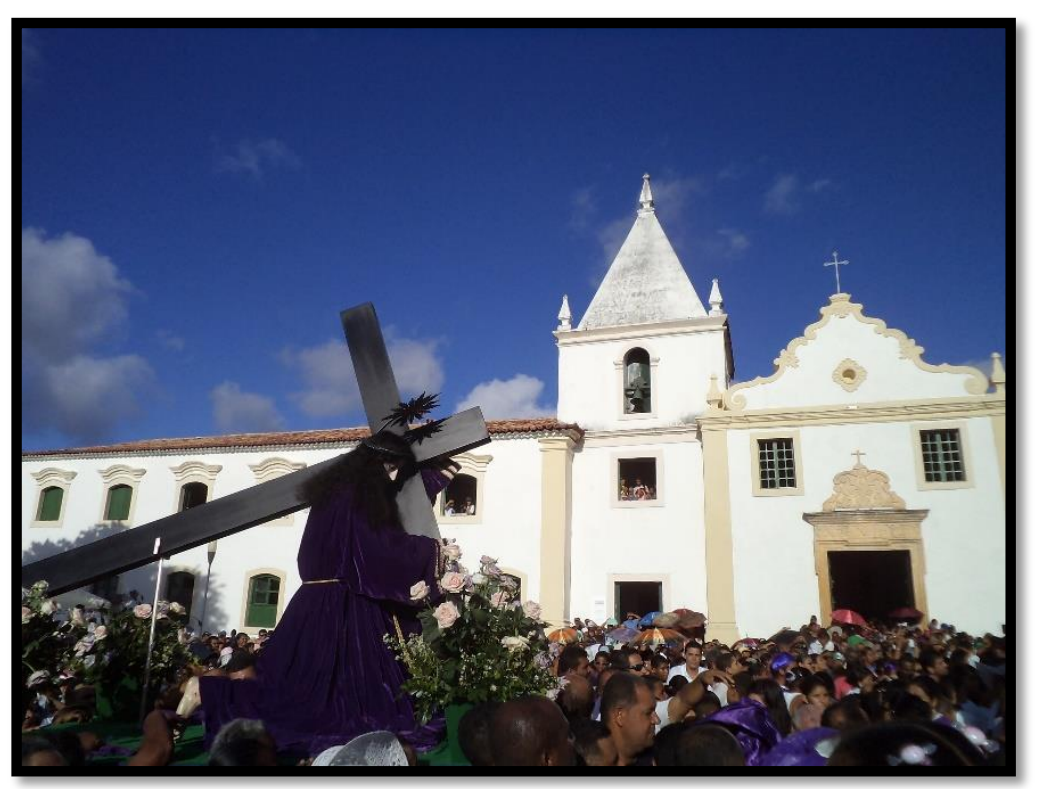

Figura 1 - Festa do Senhor dos Passos em São Cristóvão (2015)

Fonte: Acervo do autor

O período dos primórdios do evento como sendo o final do século XIX, também é citado por outros pesquisadores que já se debruçaram sobre o tema. ${ }^{4}$ Mas sabe-se que como herança das festas de irmandades do Brasil colônia, a festa em Louvor ao Senhor dos Passos já ocorria antes da data de trasferência da capital para Aracaju. De acordo com professora Verônica Nunes, ${ }^{5}$ "ao longo do século XIX quando a gente lê as narrativas sobre a Procissão de Passos, constatamos que ela era um Compromisso da Ordem Terceira do Carmo de homens leigos, que seguia a regra Carmelita. Porém, no século $X X$, não se teve a presença de religiosos carmelitas em São Cristóvão por muitos anos [...]." O fato de os carmelitas estarem por setenta anos ausentes da cidade, mudou significativamente a organização e continuidade da Festa, pois a comunidade tomou a frente nos ritos em homenagem ao Senhor dos Passos.

\footnotetext{
${ }^{4}$ Somente nas primeiras décadas do século XX é que a festa foi registrada sob a forma de análise e anuário ver: (ARAGÃO, 2012), (TELLES, 1917 apud SANTOS, 2011), (SANT'TIAGO, 2009), (SILVA, 1920).

${ }^{5}$ Professora de História e Museologia da Universidade Federal de Sergipe. Depoimento recolhido em Aracaju-Sergipe.
} 
A dois fatores é creditada a propagação devocional da imagem e a Festa, ambos relacionados ao imaginário coletivo local: o primeiro foi o achado singular da imagem no rio Paramopama, por um pescador; o segundo, ligado ao incêndio acidental que aconteceu na Igreja do Carmo Menor. Na ocasião, a imagem do Senhor dos Passos sofreu queimaduras na sua carnação, ${ }^{6}$ enchendo-se de bolhas, como se fosse pele humana. Bittencourt Júnior (2003) associa os dois acontecimentos como demonstrativos de hierofania. ${ }^{7}$

O primeiro acontecimento, relacionado ao achado da imagem no rio, perpassa não apenas pela descoberta da escultura, mas a indicação "do sagrado e a determinação de que o local da revelação não é como outro qualquer, mas sim, um espaço que deve se entender sagrado" (ELIADE, 2008). Nesse sentido, São Cristóvão se revelaria como ponto fixo absoluto, um centro para onde converge o fluxo de indivíduos atraídos para o rito de devoção nos espaços sagrados da festa.

O segundo fenômeno, embora de natureza físico-química, foi interpretado pela comunidade devota, como algo de natureza sagrada (BITTENCOURT JÚNIOR, 2003). Nesse contexto, a imagem do Cristo carregando a cruz se humaniza, tornandose um instrumento de identificação e veneração, mediador entre o homem devoto e Deus. Pereira (2003, p. 91) menciona que “a imagem sagrada não é adorada como imagem, mas justamente porque é hierofania, porque 'revela' algo que já não é imagem, mas o sagrado". Por sua vez, Rosendhal (1996, p. 27), informa que a imagem, quando adorada, nela é depositada um sentimento religioso originado da revelação da sua hierofania, logo, "não se trata de uma veneração do objeto enquanto tal, e sim da adoração de algo sagrado que ele contém e que o distingue dos demais".

A Solenidade do Senhor dos Passos é uma festa eminentemente popular, ritualística, penitencial, com exposição pública da fé, na qual o caráter emocional e sacrifical das pessoas está diretamente ligado às dores do Cristo e Maria. A Festa ao

\footnotetext{
${ }_{6}^{6}$ Pintura que imita a pele humana. Camada de pintura que reveste as partes não cobertas da anatomia, simulando a cor e a textura da carne humana. O mesmo que o termo encarnar.

7 Por hierofania entende-se meio pelo qual o sagrado se manifesta.
} 
Nosso Senhor dos Passos também é conhecida como uma 'Festa de Dor'. Uma celebração com o intuíto de reviver a dor de Cristo sendo uma espécie de Auto dramático, ambulante, barroco, com paradas denominadas 'Passos' ou estações da Via Crucis. Durante dois dias, os cortejos dentro do espaço do perímetro antigo da cidade sergipana de São Cristóvão representam momentos finais da vida de Jesus e o sofrimento de Maria

No sábado à noite logo após a missa campal, é realizada a Procissão do Depósito, com cânticos ligados aos passos da Paixão (Figura 2). A Procissão do Encontro no domingo é o momento ápice da festa. É visível o registro de emoção e de fervor religioso, com pessoas batendo palmas, e chorando no encontro das imagens de Nosso Senhor dos Passos e Nossa Senhora das Dores. Ao se encontrarem a imagens são aplaudias e louvadas.

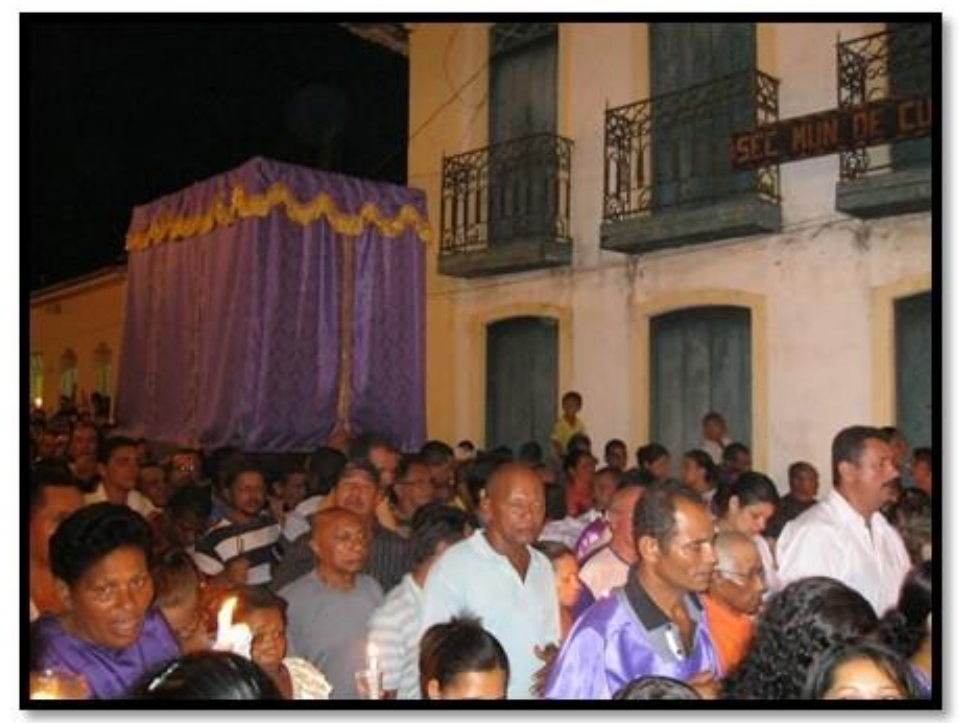

Figura 2 - Procissão do Depósito (2015)

Fonte: Acervo do autor

Em ambas as procissões acontecem paradas realizadas sempre em pontos estabelecidos e mantidos segundo a tradição da festa. Nestes locais, são erguidos pequenos altares representando o Passo a ser entoado pelos cantadores, sempre em latim. 


\section{Memórias de D. Neném sobre a Festa do Senhor dos Passos}

Os indivíduos em faixa etária avançada são detentores de acumulo de experiências oculares, tornando-se relevantes fontes da história oral (MEIHY; HOLANDA, 2014). É na velhice que os indivíduos tornam-se a memória da família, do grupo, da sociedade (BOSI, 1979). Pessoas idosas têm sido recorrentemente requisitadas para o desvelamento do passado na história, por meio de suas lembranças, estas fontes orais apontam sobre fatos da sociedade em detalhes antes esquecidos. A história oral tem se utilizado dessa técnica de pesquisa, pois é na "memória individual, que apesar de se explicar no contexto social, é aferida por meio de entrevistas nas quais o colaborador term ampla liberdade para narrar" (MEIHY; HOLANDA, 2014, p. 56).

Através das lembranças de Dona Neném recolhidas em depoimento na cidade sergipana de São Cristóvão durante o ano de 2012 foi possível entender alguns aspectos históricos da festa do Senhor dos Passos que estão extintos, em vias de desaparecer ou que se perpetuam. É nesse contexto que, a experiência compartilhada proveniente de pessoas idosas, “[...] dá-se igualmente a transmissão de experiências sociais ou da sabedoria comum da coletividade" (THOMPSON, 1998, p. 18). É por meio da memória individual e coletiva que permanecem saberes, ritos e ideias. Por meio de ambas, cristaliza-se o passado transformando-a em:

[...] um elemento constituinte do sentimento de identidade, tanto individual como coletiva, na medida em que ela é também um fator extremamente importante do sentimento de continuidade e de coerência de uma pessoa ou de um grupo em sua reconstrução de si (POLACK, 1992, p. 5).

É na memória coletiva compartilhada que a vivência da festa do Senhor dos Passos como tal, assimilada pelo grupo, torna-se "um elemento essencial do que se 
costuma chamar de identidade individual ou coletiva, cuja busca é uma das atividades fundamentais dos indivíduos e das sociedades de hoje [...]" (LE GOFF, 1990, p. 476). No entanto, é na memória individual que pessoas imprimem através das lembranças dos fatos passados a sua própria existência e auteridade. "Na experiência vivida, a memória individual formada pela coexistência, tensional e nem sempre pacífica, de várias memórias está sempre em permanente construção" (CATROGA, 2009). Com isso, estas considerações foram postas em evidência ao entrevistar a Sra. Maria Luiza dos Santos mais conhecida como Dona Neném sobre a comemoração do Senhor dos Passos.

É possível perceber nos moradores mais antigos que o passado, torna-se fator de rememoração constante e, dessa forma, suas memórias "permitem a relação do corpo presente com o passado e, ao mesmo tempo, interfere no processo atual das representações" (BOSI, 1979, p. 9). Representações de caráter sociocultural que, quando bem trabalhadas, podem se tornar produto do turismo. A memória também passa a ser constituinte de valores que fazem dela única e fator de estudo, pesquisa e atração cultural. Em documento do Ministério do Turismo (BRASIL, 2008, p. 16), se encontram afirmações que se encadeiam com a idéia de que a vivência histórica das comunidades, ao ser valorizada pelo turismo, enriquece a experiência do visitante e reforça o sentimento de pertença local.

É nesse contexto que a festa religiosa em São Cristóvão se apresenta como lugar de memória (NORA, 1993), visto que, estabelece vínculos afetivos relativos à história de vida da senhora idosa escolhida para expor suas lembranças elegidas pela memória. Este local da memória, relacionado à festa religiosa e solicitado à exposição por parte da entrevistada, ao ser evocado para o tempo presente, se atualiza.

A memória se presentifica pela lembrança individual, tornando o ato de rememorar um elemento a ser compartilhado através da experiênciaa (HALBWACHS, 2004). De acordo com a citada depoente “[...] desde o seu tempo de menina, não houve muitas mudanças no trajeto da procissão [...]". De acordo com a 
depoente o que ocorreu foram mudanças nas paradas. Segundo Maria Luiza dos Santos, no início da comemoração os passos eram rezados e cantados, diferentemente de agora que também são dramatizados e acompanhados por banda de música.

Quando questionada sobre os fiéis, ela informou que alguns devotos não se contentam apenas em olhar e venerar Nosso Senhor dos Passos, eles querem tocar a imagem, jogar roupas e muitas vezes danificando a carnação, ou até, desarticulando o braço da imagem. Segundo D. Neném “[...] teve um ano que jogaram bastantes vestes roxas em pagamento de promessa, que o braço do Senhor dos Passos descolou do corpo $[\ldots]^{\prime \prime}$.

Sobre a doçaria na festa, ainda em depoimento D. Neném acrescenta que no seu tempo de menina "[...] os doces mais vendidos na Festa de Passos eram as queijadas e as bolachinhas [...]", como atualmente ainda são. A depoente explica que a receita foi mudada por conta da farinha que não deixa as queijadinhas tão crocantes como antigamente. Essa transformação ocorreu também com as bolachinhas que deixaram de ser feitas com o leite puro de coco, para serem feitas com água dessa mesma fruta, "[...] para render mais [...], ficando segundo ela, mais duras e secas, não mais 'derretendo na boca'".

A principal via para o comércio dos doces e biscoitos é a Rua Tobias Barreto (rua em linha reta que começa em frente à Igreja Matriz da Nossa Senhora da Vitória e termina no antigo Largo do Carmo). Nas calçadas das casas localizadas dentro do perímetro entre a Matriz e as Igrejas Carmelitas (Figura 3), é possível encontrar doceiras vendendo as Queijadas, Bolachas de Goma, Sequilhos e Cocadas.

Esse ponto de venda tradicional vem de tempos passados, confirmado pela fala de D. Neném, mencionando essa rua como local de venda para as queijadas e bolachinhas desde o seu tempo de criança. No seu depoimento, D. Neném expôs que “[...] daqui até a Matriz era cheio de gente vendendo queijada [...]. Todo mundo que vinha para a Festa de Passos queria levar uma lembrança de queijada, cocada, bolachinha, para quem ficava em casa, $[\ldots]^{\prime \prime}$. 


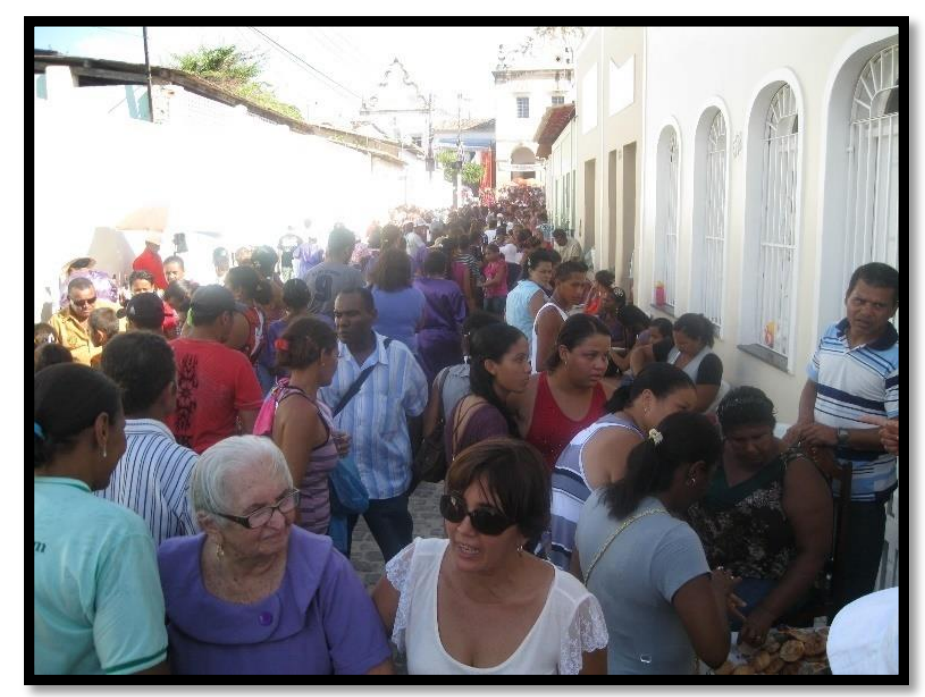

Figura 3 - Rua Tobias Barreto em São Cristóvão/SE (2015) Fonte: Acervo do autor

\section{Considerações Finais}

Ao expôr as memórias de Maria Luiza dos Santos, mais conhecida como D. Neném, a presente pesquisa externaliza aspectos da Festa de Nosso Senhor dos Passos sob a ótica das lembranças de uma depoente idosa. $\mathrm{O}$ ato de rememorar verifica-se através do discurso do passado, evocado por experiências positivas ou/e negativas.

É pela memória que fatos do passado são eleitos para serem presentificados, ocorrendo uma seleção natural do que lembrar e esquecer. O que não é dito também possui sua relevância, visto que, se inscreve em parâmetros do indizível e, que ao ser negado, se reveste de igual relevância ao que foi falado (POLACK, 1989).

Dona Neném ao expor suas lembranças traz à luz fatos da comemoração do Senhor dos Passos na cidade de São Cristóvão passiveis de serem verificados como mudanças e permanências ao longo do século da ocorrência da festa religiosa. Com tudo isto, se verificou quais memórias relativas aos aspectos da Festa do Senhor dos Passos foram priorizadas pela depoente centenária. 


\section{Referências Bibliográficas}

ARAGÃO, Ivan Rêgo. "Vinde todas as pessoas, e vede a minha dor": A Festa/Procissão ao Nosso Senhor dos Passos como Atrativo Potencial Turístico em São CristóvãoSergipe-Brasil. 2012. 198f. Dissertação (Mestrado) Cultura e Turismo - Universidade Estadual de Santa Cruz (UESC), Ilhéus-BA.

BITTENCOURT JÚNIOR, Antônio. A procissão dos penitentes do Senhor dos Passos: um estudo de comunicação na religiosidade popular na cidade de São Cristóvão no Estado de Sergipe. Rio de Janeiro, 153 p. Dissertação (Mestrado em Comunicação), Rio de Janeiro, UFRJ, 2003.

. Penitentes do Senhor dos Passos, identidade e diversidade na religiosidade popular. In: Encontro Nacional de História das Religiões / ANPUH, Maringá, 2007. p. 1-9.

BOSI, Ecléa. Memória E sociedade: lembrança de velhos. São Paulo, SP. T.A. Editor, 1979.

BRASIL, MINISTÉRIO DO TURISMO. Diretrizes para o desenvolvimento do turismo cultural. 2. ed. Brasília: MTur, 2008.

BRASIL. Inventário Nacional de Bens Móveis e Integrados: Sergipe e Alagoas, módulo 1, v. 4. Brasília: Ministério da Cultura, Instituto do Patrimônio Histórico e Artístico Nacional, Fundação Vitae, 2001.

CATROGA, Fernando. Os passos do homem como restolho do tempo: memória e o fim da História. Coimbra: Almeidina, 2009.

ELIADE, Mircea. O sagrado e o profano: a essência das religiões. Trad. Rogério Fernandes. 2. ed. São Paulo: Martins Fontes, 2008.

HALBWACHS, Maurice. A memória coletiva. Tradução de Beatriz Sidou. $2^{a}$ ed. São Paulo: Ed. Centauro, 2013.

LE GOFF, Jacques. História e memória. Tradução de Bernrado Leitão. - Campinas, SP: Editora da Unicamp, 1994.

MACENA, Lourdes. Festas, danças e folguedos: elementos de identidade local, patrimônio imaterial de nosso povo. In: MARTINS, J. C. de O. (Org.). Turismo, cultura e identidade. São Paulo: Roca, 2003. p.63-76 
MEIHY, José C. S. B; HOLANDA, Fabíola. História oral: como fazer, como pensar. 2. ed. São Paulo: Contexto, 2014.

NORA, Pierre. Entre a memória e a história: a problemática dos lugares. In: Projeto História, n 10, dez. 1993, p. 7-28.

PEREIRA, João Carlos. A linguagem do corpo na devoção popular do catolicismo. In: Revista de Estudos da Religião. São Paulo, PUC, no 3, 2003, p. 67-98.

POLACK, Michael. Memória, esquecimento, silêncio. In: Estudos históricos, Rio de Janeiro, vol. 2, n. 3, 1989, p. 3-15.

Memória e identidade social. In: Estudos históricos, Rio de Janeiro, vol. 5, no 10, 1992, p. 200-215.

ROSENDAHL, Zeny. Espaço e religião: uma abordagem geográfica. Rio de Janeiro: Eduerj, 1996.

SANT'IAGO, Serafim. Annuario Christovense ou Cidade de São Cristóvão. São Cristóvão: UFS, 2009.

SANTOS, Magno Francisco de Jesus; NUNES, Verônica Ma. Meneses. Na Trilha dos Passos do Senhor: a devoção ao Senhor dos Passos de São Cristóvão/Se. In: Revista da Fapese de Pesquisa e Extensão. Aracaju, v. 2, jul/dez. 2005. p. 97-110.

SANTOS, Magno Francisco de Jesus. Caminhos da penitência: a solenidade do Senhor dos Passos na cidade de São Cristóvão-Sergipe (1886-1920). Monografia de licenciatura em História. São Cristóvão: UFS, 2006.

SANTOS, Magno Francisco de Jesus. Pândega de promesseiros: sabores e penitência na festa de Passos em Sergipe novecentista. In: Revista Brasileira de História das Religiões. Maringá, v. III, n.9, 2011. p. 1-13.

THOMPSON, E. P. Costumes em comum: estudos sobre a cultura popular tradicional. São Paulo: Companhia da Letras, 1998. 